\title{
Proteomic analyses identify prognostic biomarkers for pancreatic ductal adenocarcinoma
}

\author{
Dingyuan Hu',2, Daniel Ansari ${ }^{3}$, Krzysztof Pawłowski ${ }^{4,5}$, Qimin Zhou $^{1}$, Agata Sasor ${ }^{6}$, \\ Charlotte Welinder ${ }^{7}$, Theresa Kristl', Monika Bauden ${ }^{1}$, Melinda Rezeli ${ }^{8}$, Yi Jiang ${ }^{2}$, \\ György Marko-Varga ${ }^{8}$ and Roland Andersson ${ }^{3}$ \\ ${ }^{1}$ Lund University, Faculty of Medicine, Department of Clinical Sciences Lund (Surgery), Lund, Sweden \\ ${ }^{2}$ Department of Gastroenterology, The Second Affiliated Hospital of Wenzhou Medical University, Wenzhou, China \\ ${ }^{3}$ Lund University, Skane University Hospital, Department of Clinical Sciences Lund (Surgery), Lund, Sweden \\ ${ }^{4}$ Department of Experimental Design and Bioinformatics, Warsaw University of Life Sciences, Warsaw, Poland \\ ${ }^{5}$ Department of Translational Medicine, Lund University, Malmö, Sweden \\ ${ }^{6}$ Department of Pathology, Skåne University Hospital, Lund, Sweden \\ ${ }^{7}$ Lund University, Department of Clinical Sciences Lund, Division of Oncology and Pathology, Lund, Sweden \\ ${ }^{8}$ Department of Biomedical Engineering, Clinical Protein Science and Imaging, Lund University, Lund, Sweden \\ Correspondence to: Roland Andersson, email: roland.andersson@med.lu.se
}

Keywords: pancreatic ductal adenocarcinoma; survival; biomarker; proteome; tumor microenvironment

Received: September 19, 2017 Accepted: October 27, $2017 \quad$ Published: January 03, 2018

Copyright: $\mathrm{Hu}$ et al. This is an open-access article distributed under the terms of the Creative Commons Attribution License 3.0 (CC BY 3.0), which permits unrestricted use, distribution, and reproduction in any medium, provided the original author and source are credited.

\section{ABSTRACT}

Pancreatic ductal adenocarcinoma (PDAC) is a highly aggressive malignancy. Here we show that shotgun and targeted protein sequencing can be used to identify potential prognostic biomarkers in formalin-fixed paraffin-embedded specimens from 9 patients with PDAC with "short" survival ( $<12$ months) and 10 patients with "long" survival (>45 months) undergoing surgical resection. A total of 24 and 147 proteins were significantly upregulated [fold change $\geq 2$ or $\leq 0.5$ and $P<0.05$; or different detection frequencies ( $\geq 5$ samples)] in patients with "short" survival (including GLUT1) and "long" survival (including C9orf64, FAM96A, CDH1 and CDH17), respectively. STRING analysis of these proteins indicated a tight protein-protein interaction network centered on TP53. Ingenuity pathway analysis linked proteins representing "activated stroma factors" and "basal tumor factors" to poor prognosis of PDAC. It also highlighted TCF1 and CTNNB1 as possible upstream regulators. Further parallel reaction monitoring verified that seven proteins were upregulated in patients with "short" survival (MMP9, CLIC3, MMP8, PRTN3, P4HA2, THBS1 and FN1), while 18 proteins were upregulated in patients with "long" survival, including EPCAM, LGALS4, VIL1, CLCA1 and TPPP3. Thus, we verified 25 protein biomarker candidates for PDAC prognosis at the tissue level. Furthermore, an activated stroma status and protein-protein interactions with TP53 might be linked to poor prognosis of PDAC.

\section{INTRODUCTION}

Pancreatic ductal adenocarcinoma (PDAC) has recently surpassed breast cancer to become the third leading cause of cancer-related mortality according to the American Cancer Society, with a 5-year survival in the single digits [1]. Despite improvements in surgical techniques and adjuvant chemoradiotherapy, the survival from the disease has not changed substantially over the past four decades. It is estimated that PDAC will surpass colorectal cancer to become the second leading cause of cancer-related mortality following lung cancer by the year 2020 [2]. The main reason underlying the low survival rate of PDAC is that most patients are diagnosed at an advanced stage, at which curatively intended surgery, no longer represents an option. Currently, CA19-9 is the only 
serum tumor marker used in the clinical management of PDAC. However, the sensitivity for CA19-9 is 79\% with a specificity of $82 \%$, limiting its use for screening purposes $[3]$.

Traditionally, PDAC has been looked upon as a gradual process associated with the sequential accumulation of genetic changes during a comparably long period of time [4]. Novel data has though implied that the development of PDAC may not be a slow and gradual process. Using whole genome sequencing, it was reported that genomic instability from mitotic errors might occur simultaneously resulting in rapid tumor development and metastases in a subset of patients [5]. These findings have been supported by a recent publication on approximately 60,000 patients with histopathologically verified PDAC where survival and metastatic spread were correlated to tumor size [6]. It was reported that already at a small tumor size up to $5 \mathrm{~mm}$, as much $30 \%$ of patients had remote cancer growth. This implies the predominant role of molecular tumor biology in determining outcome for the individual patient. It also emphasizes the need for better tools for staging, for example with novel biomarkers in order to render the necessary prognostic and predictive information and support choice of therapy in a more precision-medicine fashion.

While large scale genomics studies have provided understanding of mutational processes underlying the development of PDAC [7,8], and helped to define molecular subtypes of PDAC [9, 10], proteomics technology has accelerated our understanding of PDAC at the protein level by identifying key drivers of disease progression and biomarkers for diagnosis and targeted intervention [11, 12]. Recent proteomic studies and further validation studies have greatly expanded the pool of potential diagnostic and prognostic biomarkers in PDAC. For instance, at the tissue level, Turtoi et al. found that ASPN, LTBP2, TGFBI were overexpressed in PDAC [13], while Takadate and colleagues suggested that ECH1, GLUT1, OLFM4 and STML2 were potentially diagnostic biomarkers of PDAC [14]. Furthermore, Chen and colleagues found that PRELP, LGALS1 and RPS8 might be significant prognostic factors for pancreatic cancer [15], while another study showed that PNMA1 was associated with prolonged overall survival and might serve as a prognostic biomarker for pancreatic cancer [16]. At the plasma level, ICAM1 and TIMP1 have been proposed as biomarkers for the detection of pancreatic cancer [17]. However, these biomarkers were mostly studied in small population cohorts and thus further validation is warranted prior to clinical use.

Formalin-fixed paraffin-embedded (FFPE) tissues are used routinely in hospitals for histopathological diagnosis and staging of diseases like cancer. FFPE samples with associated clinical and histological characterization represent a valuable source of biomarker investigation. The application of mass spectrometry technology to FFPE samples has been shown to be technically feasible and highly robust for biomarker discovery and validation [18]. Specifically, deep mining of proteomes from individual samples, including membrane proteins and low-abundance proteins, broadens the possibility to discover potential biomarkers. Using proteome bioinformatic tools, the many functional partnerships and interactions that occur between proteins are revealed and put into context for molecular systems biology. In our study, we selected tissue samples from PDAC patients with divergent survival, aiming to identify prognostic biomarker panels correlating with outcome.

\section{RESULTS}

\section{Quality control and overview of proteome profiles}

To evaluate the technical reproducibility of sample handling including reduction, alkylation, precipitation and fractionation and instrument performance, we performed three independent sample preparations using an identical protein stock extracted from one sample. The intensities of proteins in the three experiments showed good correlations $\left(r^{2}=0.973,0.920\right.$ and 0.931$)$. Besides, sample preparations with and without fractionation were applied to an identical sample to compare the consistency of protein intensities from these two methods. In result, the protein intensities were in good correlation between the two methods $\left(r^{2}=0.9373\right)$. Moreover, the fractionation step achieved a remarkable enlargement of protein number being identified, which enabled a deep mining of proteome in pancreatic tissue in this study (Figure 1). Among 57 replicates from 19 samples, coefficient of variations $(\mathrm{CV})$ of $\log 2$ transformed intensities of spikedin chick lysozyme before and after normalization was $34.0 \%$ and $6.6 \%$, respectively. Around 3,000,000 peptidespectrum matches (PSMs) and 58,505 peptides with high confidence were identified, which were mapped to 4942 proteins (minimum 2 peptides per protein). Among them, 3103 proteins were identified in more than half $(\geq 5)$ of the samples in at least one group. Gene Ontology analysis was conducted based on the 3103 proteins. Cellular component analysis showed that there were 640 plasma membrane proteins, 108 cell surface proteins and 163 extracellular matrix proteins, which were considered as potential proteins for potential serum detection and also candidate therapeutic targets. Notably, PANTHER pathway analysis indicates that Integrin signaling pathway is significantly enriched (3.23 fold, $P=6.58 \mathrm{E}-19)$.

\section{Candidate prognostic proteins for PDAC}

A total of 304 proteins were differentially expressed between the "long" survival (LS) and "short" survival (SS) groups $(P<0.05)$, including 33 proteins and 271 
proteins statistically upregulated in "short" survival group and "long" survival group, respectively. Among them, 171 proteins were significantly differentially expressed between the two groups which meet the criteria: 1) SS/ LS fold change $\geq 2$ or $\leq 0.5$ and $P<0.05$; or 2 ) different detection frequencies ( $\geq 5$ samples), namely, 83 proteins that were more frequently detected $(\geq 5)$ in one group than the other one. Of these 171 proteins, 24 and 147 proteins were upregulated in "short" survival group and "long" survival group, respectively (see Figure 2).

The 171 differentially expressed proteins from 19 tissue samples were submitted to two-way unsupervised hierarchical clustering and visualized in the heat map (Figure 3A). The clustering of 19 tissue samples was in good agreement with the clinical classification. The principal component analysis further confirmed that patients with "long" survival and "short" survival were well stratified by group of differentially expressed proteins (Figure 3B). The set of differentially expressed proteins exhibited striking trend in terms of subcellular localization. David analysis showed significant overrepresentation of mitochondrial proteins (34 proteins, $P$-value 0.017 ), and specifically mitochondrial large ribosomal subunit (6 proteins, $P$-value 0.002 ) and mitochondrial respiratory chain complex I (5 proteins, $P$-value 0.033 ). PANTHER pathways analysis of differentially expressed proteins revealed overrepresentation of Wnt signaling pathway (CDH1， CSNK2A2， GNA11， CTBP2， CDH17, SMARCE1, $p$-value 0.02), followed by Alzheimer disease-presenilin pathway (MMP8, MMP9, MLLT4, CDH1, $P$-value 0.04).

In order to better assess proteins upregulated in "short" and "long" survival groups, these two sets (24 and 147 proteins, respectively), were separately submitted to

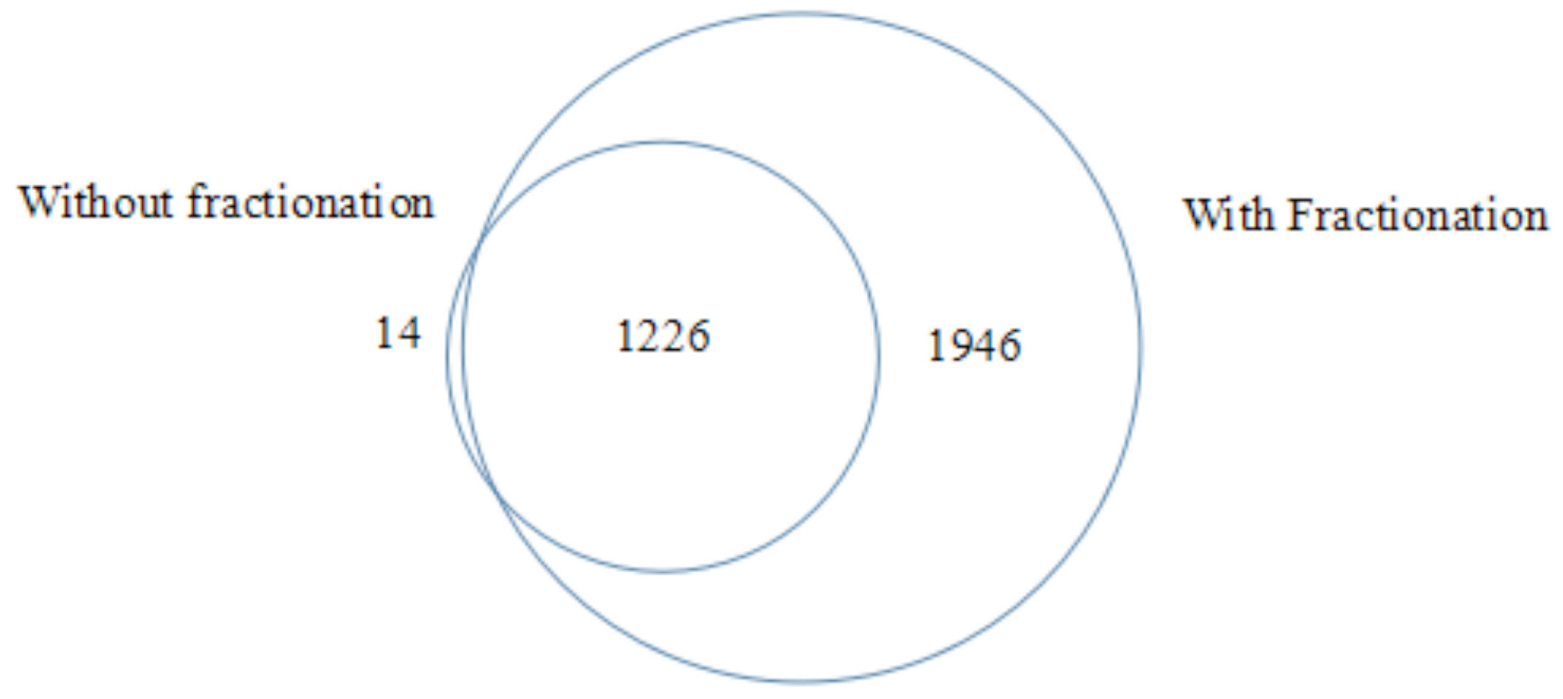

Figure 1: Venn diagram of protein numbers being identified in one identical sample by methods with and without fractionation.
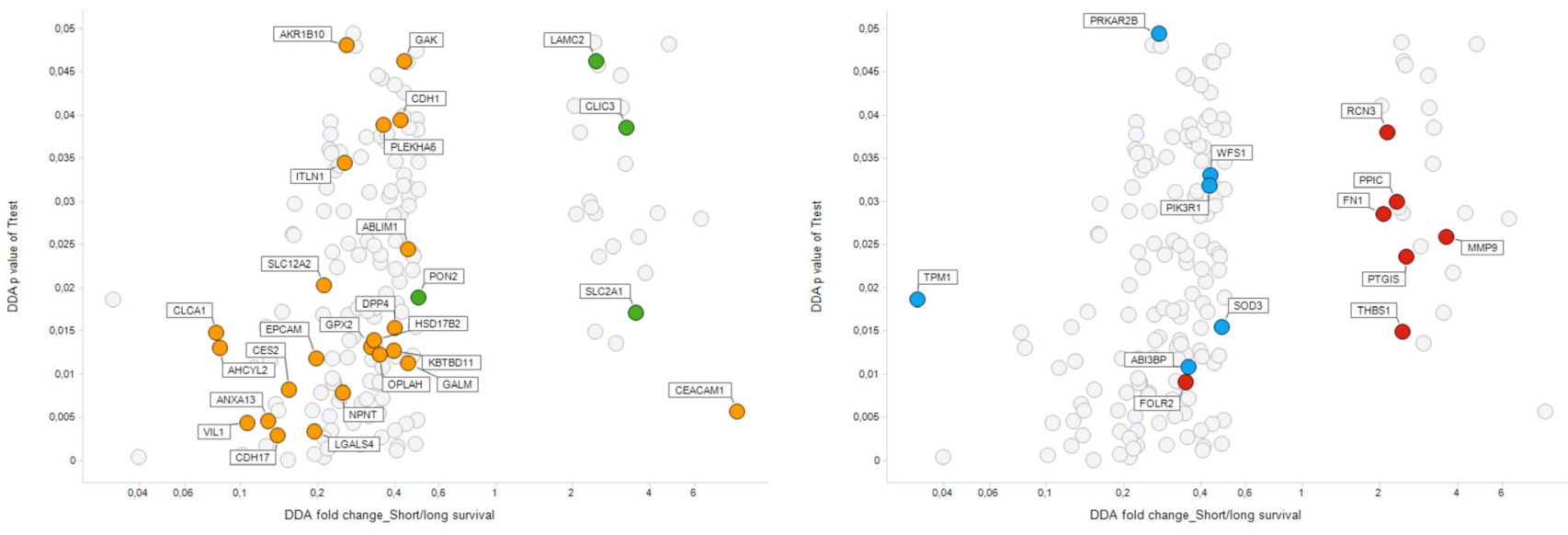

Figure 2: Volcano plot. Comparison of protein expression in short survival tumors (SS) vs long survival ones (LS). Vertical axis: $t$-test $p$-value, horizontal axis: SS/LS fold change. Colouring by proteins characteristic for PDAC subtype factors according to Moffitt et al. Left: Tumor-related factors: Green: Basal tumor, Orange: Classic tumor. Right: Stroma related-factors. Blue: Normal stroma, Red: Activated stroma. (see text). 
Panther functional analysis. Among proteins upregulated in the "long" survival group, remarkably overrepresented were mitochondrial proteins ( $P$-value $3 \mathrm{e}-5)$, which translated into overrepresentation of oxidoreductase activity ( $P$-value $1.8 \mathrm{e}-3)$. Among proteins upregulated in the "short" survival group, overrepresented were secretory vesicle proteins ( $P$-value $5 \mathrm{e}-6)$ and extracellular proteins ( $P$-value $4 \mathrm{e}-4)$. This was related to overrepresentation of activities such as peptidase activity ( $P$-value $2.5 \mathrm{e}$ $2)$, collagen binding ( $P$-value $4.8 \mathrm{e}-4)$, heparin binding ( $P$-value 7 e-6) and lipid binding ( $P$-value 3 e- 2$)$.

STRING database [19] was employed to investigate the functional and physical protein interactions among the 171 differentially expressed proteins (Figure 4). Since TP53 and KRAS were essential in the pathogenesis of pancreatic cancer, these two proteins were manually added to identify potentially related pathways. With high confidence (minimum required interaction score 0.700 ), a total of 86 protein-protein interactions were observed and they were significantly enriched based on the given protein nodes $(P$-value $<0.001)$, indicating that these differentially expressed proteins are at least partially biologically connected. Seven proteins clustered in a tight interaction network centered on TP53, including CDH1, THBS1, MMP9, EPCAM, WDR5, CSNK2A2, PADI4. Of this protein cluster, CDH1 also closely

A
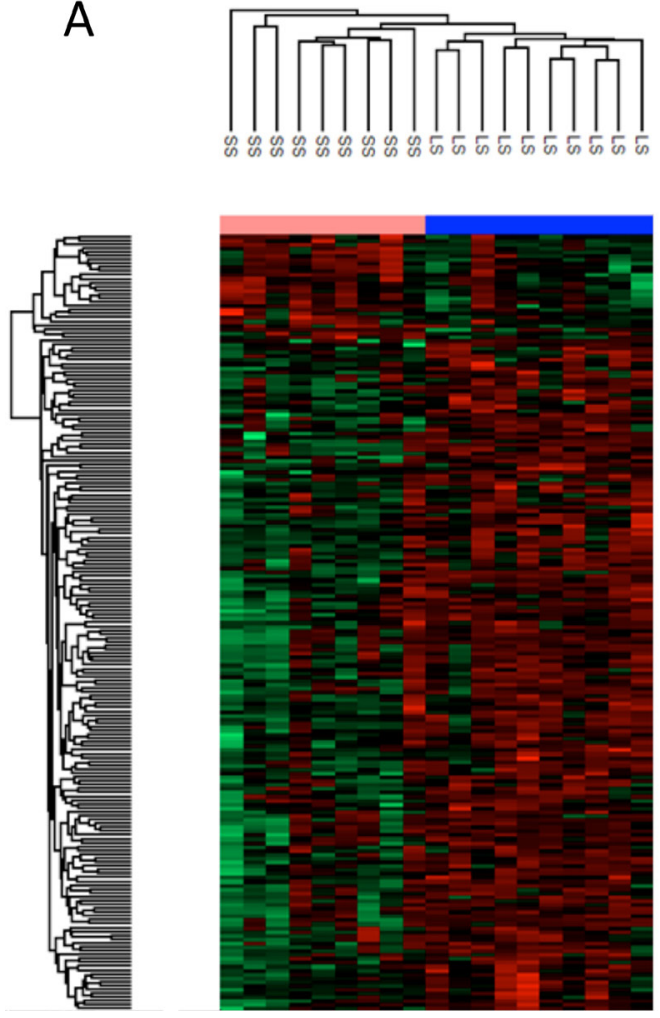

interacts with CDH17, PIK3R1, NDRG2, CTBP2, MMP9 and EPCAM while THBS1 is centered by FN1, DPP4 and MMP9. Besides, intensive interactions were also observed in the other three clusters of proteins, which were related to respiratory electron transport (COX5B, UQCRB, NDUFS5, NDUFA4, NDUFAB1, NDUFB6 and NDUFB8), mitochondrial translation (MRPL37, MRPL2, MRPL3, MRPL16, MRPL19 and MRPL23) and mRNA Splicing (PRPF4, POLR2C, MAGOH, PLRG1, CWC15 and PHF5A).

A complementary Ingenuity Pathway Analysis (IPA), using curated, literature-derived relationships, showed a picture similar to the STRING analysis (Figure 5). Top canonical pathways, which were significantly enriched among proteins differing between the "short" survival group and "long" survival group, included Oxidative Phosphorylation and Mitochondrial Dysfunction. For example, the differentially expressed proteins amounted to 7 out of 22 Oxidative Phosphorylation pathway proteins ( $P$-value 0.002$)$. Similarly to the non-curated networks generated by STRING, also Ingenuity analysis yielded tightly connected relationship subnetworks, built around protein hubs, which are known PDAC actors, even if these hub proteins were not themselves differentially expressed. These subnetworks are constructed automatically as dense subsets of global network of literature-derived

\section{B}

Figure 3: (A) Heat map of differentially expressed proteins in pancreatic cancer with long survival (LS) and short survival (SS). The heat map visualized two-way unsupervised hierarchical clustering of 171 differentially expressed proteins in pancreatic cancer patients with short survival (SS) compared to those with long survival (LS) $(P<0.01$, SS/LS fold Change $\geq 2)$. (B) Global principal component analysis of protein profiles in 19 samples. Dots representing pancreatic cancer (PC) patient samples with long survival (blue) and short survival (red) were well clustered, which was in good agreement with the clinical classification. 
relationships between proteins and genes. First such subnetwork was centered on Akt kinase and mitochondrial complex 1 proteins. The second subnetwork was centered on NFkB and TCF transcription factors. The hubs of the third subnetwork were the ERK kinases, collagens and matrix metalloproteases (MMPs). The fourth subnetwork was focused on HNF4A and mitochondrial ribosomal proteins.

Additionally, an IPA analysis of possible upstream regulators of the differentially expressed proteins yielded a mechanistic network regulated by HNF1A (TCF1) and CTNNB1, a well-known cancer regulatory hub important for the Wnt signaling pathway. The HNF1A mechanistic network was significant, with $p$-value 4.2E-05, and included 8 proteins from the differentially expressed list: ALDH3A2, CEACAM1, CRAT, EPCAM, GPX2, HSD17B2, MUC6 and PCCA, see Figure 6.



\section{Verification of candidate prognostic proteins by targeted MS/MS}

To evaluate the potential candidate proteins, 171 differentially expressed proteins from the discovery phase were selected for targeted proteomics study. Unfortunately, 98 proteins of them failed in the PRM approach. Finally, 73 proteins were successfully detected and scheduled in one assay panel. The proteins were detectable in all samples. Thirty-six proteins were differentially expressed between the two groups, including 7 proteins and 29 proteins statistically upregulated in "short" survival group and "long" survival group, respectively $(P<0.05)$. Of them, seven proteins were significantly upregulated (SS/ LS fold change $>1.5$ ) in patients with "short" survival (MMP9, CLIC3, MMP8, PRTN3, P4HA2, THBS1, FN1), while 18 proteins were significantly upregulated (SS/

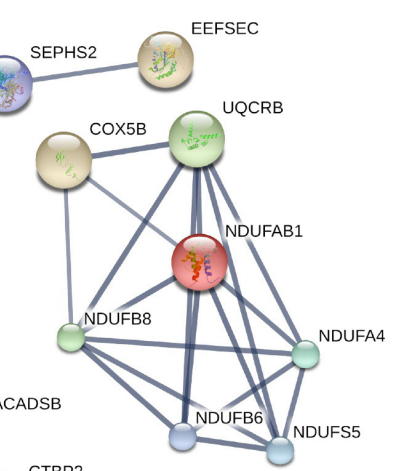

СTBP2

NDRG2
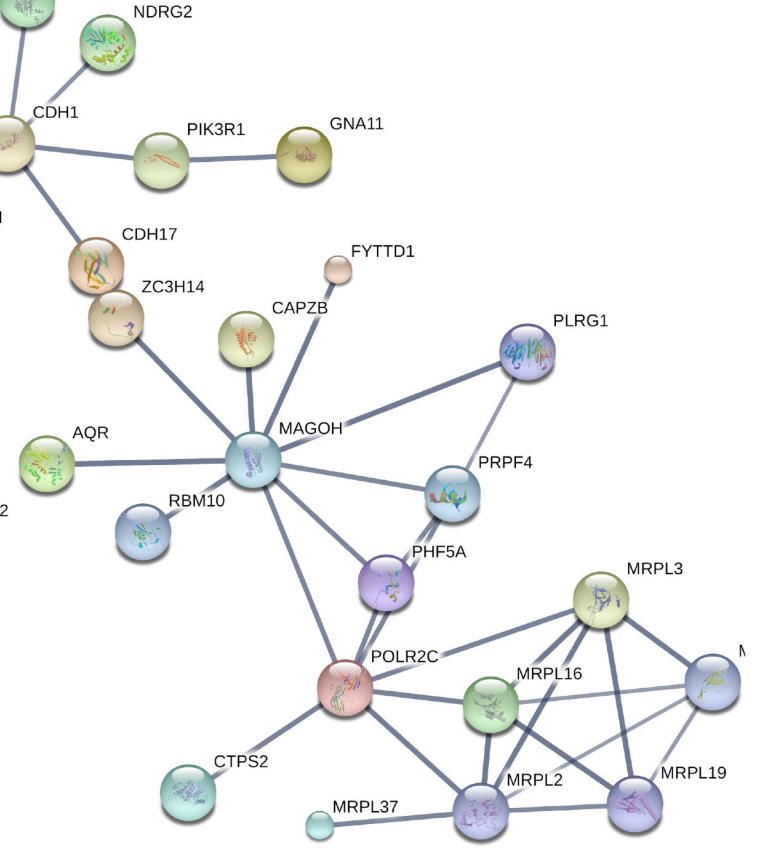

Figure 4: Protein-protein interactions among prognostic candidate proteins. Protein-protein interactions of the 171 dysregulated proteins extracted from the STRING database. TP53, KRAS were manually added to identify potentially related pathways. Notably, seven proteins were centered on TP53, including CDH1, THBS1, MMP9, EPCAM, WDR5, CSNK2A2, PADI4. 
LS fold change $<0.5$ ) in patients with "long" survival (TMED4, GPD1L, SOD3, NPNT, ABHD14B, ACADSB, DHRS1, EPCAM, WDR82, HDHD2, TPPP3, CHGA, LGALS4, TTC38, COQ9, CES2, VIL1, CLCA1) (Figure 7 and Table 1). After the expression values of each protein were divided into two groups: lower expression ( 9 cases) and higher expression (10 cases), Kaplan-Meier analysis showed that four proteins were significantly negatively correlated to the survival months (TPPP3, WDR82, LGALS4 and EPCAM, $P$ values were $<0.001,0.008$, 0.020 and 0.010 , respectively) (Figure 8).

\section{DISCUSSION}

PDAC is considered one of the most aggressive and lethal forms of human cancer. However, there exists a small proportion of patients that actually reach a comparably "long" survival after surgical resection and adjuvant chemotherapy, even when they have "advanced stage" disease (size) or other markers of poor prognosis


[20-22]. There have been very few studies relating global protein expression to survival in $\operatorname{PDAC}[14,23]$. The characterization of protein profiles at the tissue level might help to understand better the molecular basis of PDAC progression and identify potential biomarkers for diagnosis and prognosis of the disease. In this study, we have established a comprehensive method for proteome deep mining based on formalin-fixed paraffin-embedded PDAC tissues, which led to discovery of around 5000 proteins, making it possible to detect low abundance proteins and hydrophobic membrane proteins. A total of 171 proteins were dysregulated in patients with "short" survival compared to those with "long" survival. A further validation panel, targeting 73 of the differentially expressed proteins confirmed that 7 and 18 proteins, were upregulated in the "short" survival and the "long" survival patients, respectively.

In this study, several aspects accounting for the aggressiveness of PDAC have been highlighted. Among well-known hallmarks of cancer metabolism, shift from
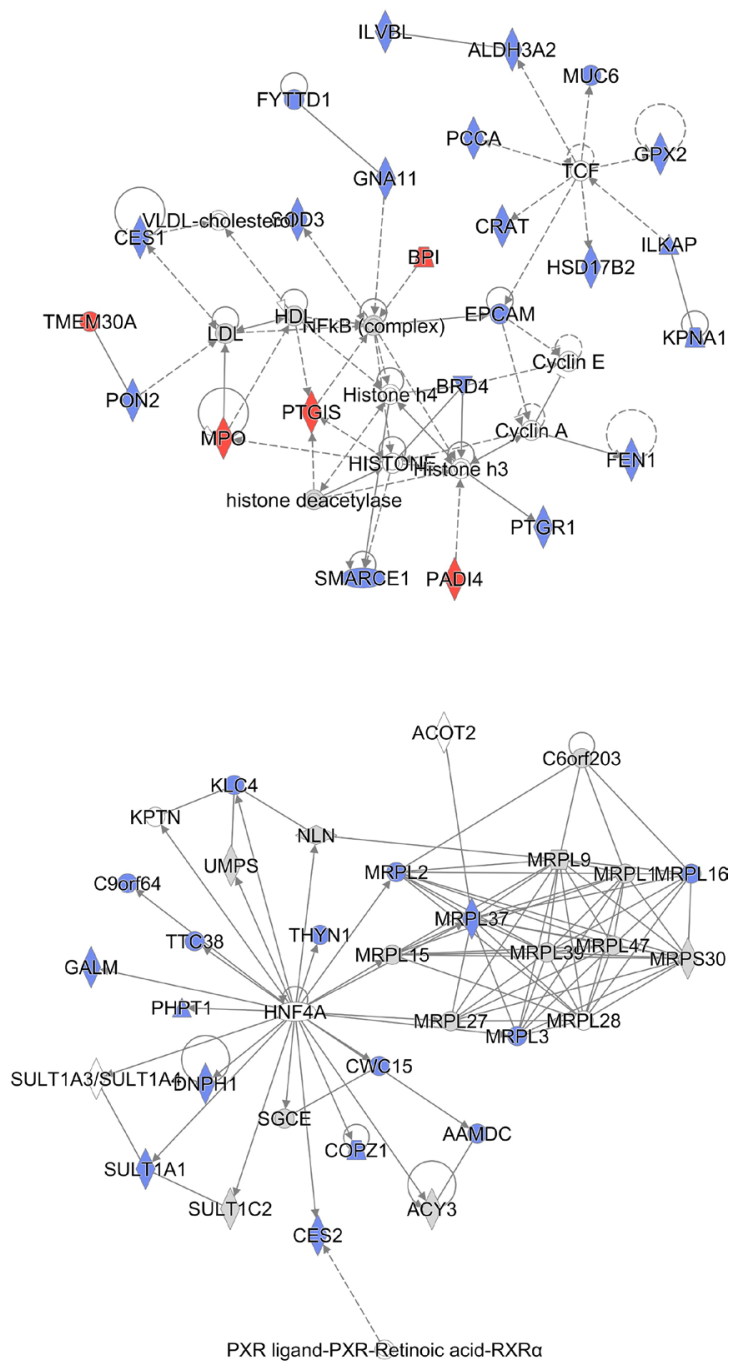

Figure 5: Protein-protein relationships among prognostic candidate proteins extracted by the Ingenuity IPA analysis. Top four subnetworks shown. Red: proteins upregulated in short survival patients. Blue: proteins upregulated in long survival patients. 
oxidative phosphorylation towards glycolysis is wellknown [24], and specific glucose metabolic phenotype was proposed for pancreatic cancer [25]. Strikingly, in the current study, this metabolic shift was seen as generally lower expression of mitochondrial proteins in "short" survivors. Most notably, this affected a set of mitochondrial respiratory chain complex I proteins (likely resulting in lowered oxidative phosphorylation) and a set of mitochondrial ribosomal proteins (likely resulting in lowered mitochondrial translation rates).

Another cancer metabolism hallmark is the deregulation of glucose intake [24]. Glucose transporter 1 (GLUT1), also known as facilitated glucose transporter member 1 (SLC2A1), is a pivotal rate-limiting element in the transport of glucose in malignant cells. GLUT1 has also been implicated in the pathogenesis of PDAC. Nagarajan et al. found that by stimulating GLUT1mediated glucose transport, paraoxonase 2 favored the tumor growth and metastasis of PDAC [26]. It has also been reported that $\mathrm{HMGB} 2$ predicts poor prognosis in PDAC by facilitating HIF1- $\alpha$-mediated glycolysis through the expression of GLUT1 [27]. NDRG1, a tumor suppressor, was also shown to inhibit cancer metabolism in PDAC partly through the regulation of GLUT1 gene [28]. High levels of GLUT1 have been previously correlated to poor outcome in PDAC $[29,30]$. Accordingly, in our results, GLUT1 was significantly upregulated in "short" survivors. Recently, GLUT1 was shown to be a promising target in pancreatic cancer stem cells in mice [31].

Several differentially expressed proteins (CDH1, THBS1, MMP9, EPCAM, WDR5, CSNK2A2 and PADI4) have a close interplay with TP53, which is frequently mutated and progressively involved in pancreatic cancer [32-35]. THBS1, MMP9 and PADI4 were upregulated in patients with "short" survival, while the other four proteins were upregulated in patients with "long" survival.



Figure 6: TCF1 and CTNNB1 are hubs of a mechanistic upstream regulatory network (IPA). Red symbols: proteins upregulated in short survival patients. Blue symbols: proteins upregulated in long survival patients. Orange edges: relationships predicted as activating. Blue edges: relationships predicted as inhibitory. Yellow edges: relationships inconsistent with downstream protein state. 
Table 1: List of candidate prognostic biomarkers for pancreatic cancer

\begin{tabular}{|c|c|c|c|c|c|c|c|c|c|}
\hline \multirow[b]{2}{*}{ Entry } & \multirow[b]{2}{*}{ Gene } & \multicolumn{4}{|c|}{ DDA } & \multicolumn{3}{|c|}{ PRM } & \multirow[b]{2}{*}{ Description } \\
\hline & & $\begin{array}{l}\text { LS } \\
\text { Freq. }\end{array}$ & $\begin{array}{c}\text { SS } \\
\text { Freq. }\end{array}$ & $P$ value & $\begin{array}{l}\text { SS/LS Fold } \\
\text { change }\end{array}$ & Pep. no. & $P$ value & $\begin{array}{l}\text { SS/LS Fold } \\
\text { change }\end{array}$ & \\
\hline P14780 & MMP9 & 10 & 9 & 0.026 & 3.62 & 2 & 0.045 & 4.44 & Matrix metalloproteinase- 9 \\
\hline O95833 & CLIC3 & 1 & 6 & 0.039 & 3.25 & 2 & 0.010 & 3.42 & $\begin{array}{l}\text { Chloride intracellular channel } \\
\text { protein } 3\end{array}$ \\
\hline P22894 & MMP8 & 1 & 6 & 0.029 & 4.28 & 1 & 0.046 & 3.06 & Neutrophil collagenase \\
\hline P24158 & PRTN3 & 7 & 9 & 0.022 & 3.85 & 2 & 0.031 & 2.98 & Myeloblastin \\
\hline O15460-2 & P4HA2 & 6 & 9 & 0.025 & 2.88 & 2 & 0.029 & 2.66 & $\begin{array}{l}\text { Isoform IIa of Prolyl } \\
\text { 4-hydroxylase subunit alpha-2 }\end{array}$ \\
\hline P07996 & THBS1 & 10 & 9 & 0.015 & 2.46 & 2 & 0.028 & 2.01 & Thrombospondin-1 \\
\hline $\mathrm{P} 02751$ & FN1 & 10 & 9 & 0.029 & 2.07 & 2 & 0.034 & 1.92 & Fibronectin \\
\hline A8K7I4 & CLCA1 & 5 & 0 & 0.015 & 0.08 & 1 & 0.029 & 0.05 & $\begin{array}{l}\text { Calcium-activated chloride } \\
\text { channel regulator } 1\end{array}$ \\
\hline P09327 & VIL1 & 10 & 5 & 0.004 & 0.11 & 2 & 0.008 & 0.12 & Villin-1 \\
\hline O00748 & CES2 & 5 & 0 & 0.008 & 0.15 & 2 & 0.029 & 0.16 & Cocaine esterase \\
\hline O75208 & COQ9 & 8 & 2 & 0.004 & 0.27 & 2 & 0.004 & 0.19 & $\begin{array}{l}\text { Ubiquinone biosynthesis } \\
\text { protein COQ9, mitochondrial }\end{array}$ \\
\hline Q5R3I4 & TTC38 & 10 & 5 & 0.017 & 0.21 & 1 & 0.035 & 0.20 & $\begin{array}{l}\text { Tetratricopeptide repeat } \\
\text { protein } 38\end{array}$ \\
\hline P56470 & LGALS4 & 10 & 8 & 0.003 & 0.19 & 2 & 0.005 & 0.23 & Galectin-4 \\
\hline P10645 & CHGA & 7 & 2 & 0.038 & 0.23 & 2 & 0.025 & 0.27 & Chromogranin-A \\
\hline Q9BW30 & ТРРP3 & 9 & 1 & 0.001 & 0.10 & 1 & 0.000 & 0.28 & $\begin{array}{l}\text { Tubulin polymerization- } \\
\text { promoting protein family } \\
\text { member } 3\end{array}$ \\
\hline Q9H0R4 & HDHD2 & 10 & 5 & 0.005 & 0.22 & 2 & 0.026 & 0.30 & $\begin{array}{l}\text { Isoform } 2 \text { of Haloacid } \\
\text { dehalogenase-like hydrolase } \\
\text { domain-containing protein } 2\end{array}$ \\
\hline Q6UXN9 & WDR82 & 7 & 2 & 0.039 & 0.22 & 1 & 0.023 & 0.31 & $\begin{array}{l}\text { WD repeat-containing protein } \\
82\end{array}$ \\
\hline P16422 & EPCAM & 8 & 2 & 0.012 & 0.20 & 1 & 0.021 & 0.33 & $\begin{array}{l}\text { Epithelial cell adhesion } \\
\text { molecule }\end{array}$ \\
\hline Q96LJ7 & DHRS1 & 7 & 1 & 0.007 & 0.24 & 1 & 0.017 & 0.37 & $\begin{array}{l}\text { Dehydrogenase/reductase } \\
\text { SDR family member } 1\end{array}$ \\
\hline P45954 & ACADSB & 9 & 3 & 0.017 & 0.15 & 2 & 0.026 & 0.38 & $\begin{array}{l}\text { Short/branched chain specific } \\
\text { acyl-CoA dehydrogenase, } \\
\text { mitochondrial }\end{array}$ \\
\hline Q96IU4 & ABHD14B & 10 & 9 & 0.007 & 0.31 & 2 & 0.013 & 0.46 & $\begin{array}{l}\text { Alpha/beta hydrolase domain- } \\
\text { containing protein 14B }\end{array}$ \\
\hline Q6UXI9-6 & NPNT & 10 & 3 & 0.008 & 0.25 & 1 & 0.016 & 0.46 & Isoform 6 of Nephronectin \\
\hline P08294 & SOD3 & 10 & 9 & 0.015 & 0.48 & 2 & 0.003 & 0.47 & $\begin{array}{l}\text { Extracellular superoxide } \\
\text { dismutase }[\mathrm{Cu}-\mathrm{Zn}]\end{array}$ \\
\hline Q8N335 & GPD1L & 9 & 4 & 0.030 & 0.16 & 2 & 0.010 & 0.47 & $\begin{array}{l}\text { Glycerol-3-phosphate } \\
\text { dehydrogenase 1-like protein }\end{array}$ \\
\hline Q7Z7H5 & TMED4 & 10 & 4 & 0.002 & 0.13 & 2 & 0.040 & 0.48 & $\begin{array}{l}\text { Transmembrane emp24 } \\
\text { domain-containing protein } 4\end{array}$ \\
\hline
\end{tabular}

Abbreviations: DDA:data-dependent acquisition; PRM:parallel reaction monitoring; LS: long survival; SS: short survival; Pep. No: number of peptides for proteins in the PRM panel. Freq.: number (frequency) of cases in which the protein was detected.

The predictive potential of THBS1 and MMP9 for the prognosis of pancreatic cancer has been reported in a few previous studies [14, 36, 37]. It has been suggested that TP53 inhibits angiogenesis by the regulation of THBS1 synthesis [38], while MMP9 degrades the extracellular matrix component and facilitates the invasion of tumors. PADI4 acts as a transcriptional corepressor for TP53 [39]. A study revealed that the TP53-PADI4 pathway participated in the response to DNA damage, nuclear fragmentation and TP53-mediated cell death 



Figure 7: Boxplot of intensities of prognostic proteins from PRM phase in PDAC patients with "short" survival (SS) compared to "long" survival (LS) (all $\boldsymbol{P}<\mathbf{0 . 0 5}$ ). Seven proteins (THBS1, P4HA2, MMP9, MMP8, FN1, CLIC3, PRTN3) were significantly upregulated (SS/LS fold change $>1.5$ ) in patients with SS while CLCA1 were significantly upregulated (SS/LS fold change $<0.5$ ) in patients with LS. 
[40]. Inhibition of TP53 was also implicated in the downregulation of $\mathrm{CDH} 1$ and cell invasion in invasive carcinoma [41]. Notably, CDH1 has functional protein associations with differentially expressed proteins in our study including CDH17, PIK3R1, NDRG2, CTBP2, MMP9 and EPCAM according to the STRING database. Kaplan-Meier analysis showed that the expression of EPCAM was inversely correlated to the survival (months) of pancreatic cancer. It has been found that the TP53 protein negatively regulates EPCAM expression by binding to a response element within the EPCAM gene [42]. Higher expression of EPCAM is associated with an improved outcome in pancreatic cancer by suppressing cell activity $[43,44]$.

A histological hallmark of PDAC is that tumor cells are surrounded by as much as $90 \%$ stroma consisting of proliferating myofibroblast-like cells (pancreatic stellate cells), immune cells and inflammatory cells and extracellular matrix components such as collagen, fibrinogen, hyaluronan, and fibrin [45]. The microenvironment of pancreatic adenocarcinoma has a complex role in tumor growth and therapeutic response. While the existence of a dense stroma is thought to


promote tumor progression and metastasis [46, 47], this concept has been challenged by recent experimental evidence showing that some elements of the stroma may actually restrain the tumor arguing for stromal reshaping rather than pure depletion [48-50]. A number of clinical trials targeting the tumor-stroma interactions in PDAC are ongoing, however, the results seem to be inconclusive. Therefore, a further understanding of the tumor microenvironment is needed. A recent large-scale genomics analysis of PDAC by Moffitt et al. employed socalled virtual microdissection to elucidate tumor subtypes and to account for cellular heterogeneity in tumor samples, typically containing a large amount of stroma alongside the tumor itself [10]. They linked poor prognosis to sets of proteins named "activated stroma factors" as well as "basal tumor factors". Strikingly, our data parallels closely to their results. As seen in Figure 2, proteins classified by Moffitt as "activated stroma factors" and "basal tumor factors" were upregulated in short survival patients while proteins classified as "normal stroma factors" and "classic tumor factors" were upregulated in long survival patients. The proteins characteristic for these tumor features made up as much as approximately $20 \%$ of differentially
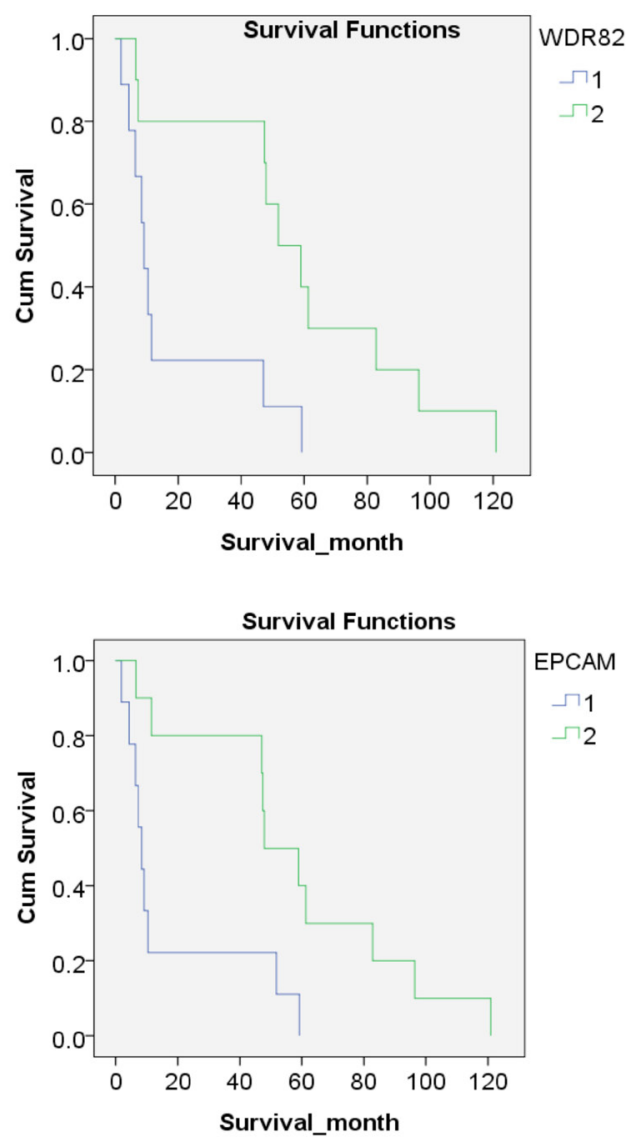

Figure 8: Kaplan-Meier analysis of protein expression. According to the expression of each protein, patients were divided into two groups: lower expression (9 cases, Blue line, marked by 1) and higher expression (10 cases, green line, marked by 2), Kaplan-Meier analysis showed that four proteins were significantly correlated to the survival months (TPPP3, WDR82, LGALS4 and EPCAM, $P$ values were $<0.001,0.008,0.020$ and 0.010 , respectively). 
expressed proteins. Our results are in accordance with the findings of Moffitt et al. and support the idea that an activated stroma state may be linked to poor prognosis [10].

In our study, many potentially prognostic proteins are related to the microenvironment of pancreatic cancer. Reactome pathway analysis revealed that 9 of the differentially expressed proteins were involved in extracellular matrix organization, including THBS1, PLOD1, LAMC2, P4HA2, MMP9, MMP8, FN1, CDH1 and CEACAM1. Four proteins participating in collagen formation, PLOD1, LAMC2, P4HA2 and MMP9, were all upregulated in patients with "short" survival compared to those with "long" survival. In comparison, out of five proteins participating in degradation of the extracellular matrix, four (LAMC2, FN1, MMP8 and MMP9) were upregulated and one (CDH1) was downregulated in the poor outcome group. This to some extent again suggests that the microenvironment in "short" survival patients was more activated, both in the formation and degradation of the extracellular matrix, which is believed to provide support to the surrounding tissues and serve as a physical barrier to drug delivery in PDAC [51]. Our study also revealed several collagen associated proteins as potential prognostic biomarkers, including P4HA2, THBS1 and FN1. P4HA2 participates in the biosynthesis of collagens by catalyzing the post-translational formation of 4-hydroxyproline in -Xaa-Pro-Gly- sequences in collagens. Studies have shown that the expression of P4HA2 were upregulated in the oral cavity in squamous cell carcinoma, papillary thyroid cancer, and breast cancer [52]. Furthermore, silencing P4HA2 or treatment with the P4HA inhibitor suppresses breast cancer progression by reducing tumor growth and a metastasis, which is accompanied by reduced collagen deposition, indicating its potential role as therapeutic target. FN1 has been suggested as a prognostic biomarker for pancreatic cancer in a proteomics study [14]. FN1 binds to its receptors such as integrins, inducing distinct signals to promote tumor angiogenesis and migration of PDAC cells [53]. A related molecule, regulator of integrin recycling, the CLIC3 intracellular chloride channel which drives invasiveness of pancreatic cancer is also upregulated in "short" survivors in the current study [54].

Two upstream regulators identified in our prognostic study, TCF1 and CTNNB1, emphasized the potential role of Wnt signaling pathway whose improper activation is responsible for establishment of cancer stem cells [55]. It has been recently reported that the disruption of nuclear complexes of CTNNB1 and HNF1A suppressed pancreatic tumor growth [56]. Wnt signaling has been widely implicated in cancer, especially colorectal cancer, in which mutation of key regulatory factors of the Wnt pathway (mainly APC and CTNNB1), was found in ninety percent of tumors, resulting in activation of the Wnt pathway [57-58]. However, the impact of Wnt signaling in PDAC is less clear. Although mutations of key Wnt pathway components are uncommon in PDAC, DNA methylation and expression status of multiple genes are involved in the regulation of Wnt pathway [59]. Nuclear localization of $\beta$-catenin is also regularly found in PDAC [60]. Inhibition of Wnt signaling using either a Wnt antagonist or a therapeutic monoclonal antibody in mice has been found to delay PDAC formation [61].

We have also noticed that some proteins mainly derived from polymorphonuclear neutrophils (PMNs), including MMP8, MMP9, MPO and PRTN3, were significantly upregulated in "short" survival patients. PMNs have received attention in the context of inflammation-driven tumorigenesis [62]. More neutrophils were found to be infiltrated in tumor cells in PDAC patients with poor survival $[63,64]$. It is suggested that neutrophil-derived matrix-degrading proteases such as MMP8 and MMP9, might modulate the composition of the extracellular matrix and facilitate metastasis [65]. However, the expression of MMP8 and MMP9 can also be detected in tumor cells in patients with PDAC [66]. MMPs are also part of the apoptotic process: they cleave $\mathrm{CDH} 5$, PECAM1 and CDH1 during apoptosis of endothelial or epithelial cells [67]. PRTN3, also known as Myeloblastin and c-ANCA, is implicated in degradation of elastin, fibronectin, laminin, vitronectin, and collagen types I, III, and IV in in-vitro studies. Furthermore, PRTN3 has been shown to be involved in the degradation of extracellular matrix (ECM) proteins [68]. G12C mutation in the KRAS gene is associated significantly with an altered activity of PRTN3 in pulmonary adenocarcinomas [69]. Downregulation of PRTN3 has also been reported to inhibit proliferation and induces differentiation of promyelocyte-like leukemia cells [70].

In the light of the differential expression of several extracellular proteases, MMP8, MMP9, PRTN3 and DPP4, another protein, CLCA1, merits special mention. It is a novel self-cleaving extracellular metalloprotease [71, 72] and is a homologue of likely tumor suppressors, CLCA2 and CLCA4 [73, 74]. Low expression level of CLCA1 was observed to be linked to poor prognosis in colorectal cancer and CLCA1 itself has been proposed as a prognostic marker $[75,76]$. Thus, it is an attractive hypothesis that CLCA1 has a role in tumor suppression in PDAC, either by interaction with tumor microenvironment or by proteolytic activation of yet undiscovered substrates. Another explanation of the link between CLCA1 expression and survival is the confirmed role of this protein in modulating the TMEM16A/ANO1 $\mathrm{Ca}^{2+}$-activated chloride channel $[72,77]$. Ion channels in general, and $\mathrm{Ca}^{2+}$-activated chloride channels in particular are known to be involved in regulating cell proliferation, cell migration and metastasis and are believed to be important emerging cancer drug targets in cancer [78, 79], particularly in pancreatic cancer where they may be mediating interactions with the tumor microenvironment [80]. 
Apart from dysregulated pathways and processes, several of the proteins differentiating "long" and "short" survivors were previously noted as potential tumor markers. FAM96A, upregulated in "long" survivors, has been previously shown to regulate the iron-sulphur cluster assembly [81] and was reported to be a tumor suppressor [82]. CDH1 and CDH17 are also upregulated in "long" survivors. CDH17 is a known gastric cancer marker [83] while upregulation of $\mathrm{CDH} 1$ inhibits pancreatic cancer metastasis [84]. Another potential prognostic biomarker upregulated in "long" survivors in this study, LGALS4, was proposed as exocrine-like subtype PDAC marker [85]. Its homologue, LGALS1, has been previously reported to be associated with long-term survival in PDAC [15].

Another novel observation notable among proteins significantly correlated to survival is the UPF0553 protein C9orf64. This is a typical example of an interesting protein whose obscure gene symbol makes it likely to be ignored in large-scale studies [86]. In fact, C9orf64 is a protein of Q salvage family in the Pfam database (PF10343, previously called DUF2419). Similar to DNA glycosidases and ribonucleoside hydrolases, it is involved in salvaging the micronutrient queuosine [87]. The importance of queuosine, which is involved in tRNA covalent modifications [88] is starting to be appreciated, as its roles in modulating cell proliferation are elucidated and correlation of queuosine deficiency of tRNA to severity of malignancy is revealed [89]. Thus, our results provide the first hypothesis that a link may exist between queuosine modifications and PDAC.

In conclusion, we have identified several tumorexpressed proteins that offer prognostic information in PDAC. Of note, TP53 related proteins and neutrophilderived proteins were upregulated in PDAC patients

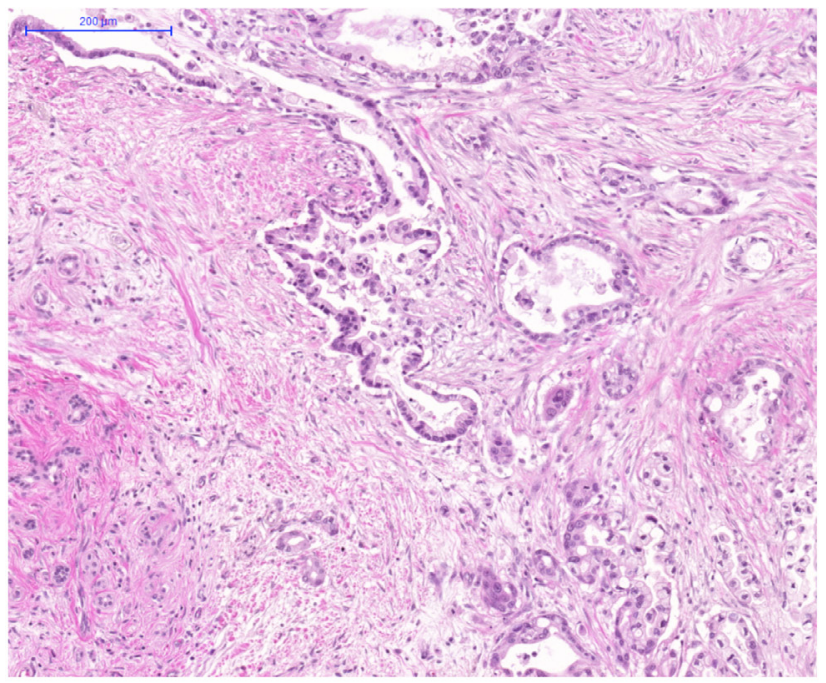

with poor survival, supporting their potential role in tumor progression. Our results indicate that the tumor microenvironment, with an activated stroma state, is closely related to disease progression. The findings also highlight the importance of the Wnt signaling pathway. Nevertheless, there are some limitations of the present study that deserve to be mentioned. Firstly, by employing a label-free quantification, only a relative quantification was possible and the absolute upregulation or downregulation of proteins in each survival group remains unknown. Incorporating corresponding normal tissues would also be of value. Secondly, the prognostic significance of the biomarker candidates needs to be validated in larger cohorts with alternative approaches, which are more accessible in the clinic, such as immunohistochemistry and tissue microarray technology. Finally, we recommend further in-depth analysis into the mechanistic role of identified biomarker candidates in order to better understand the pathophysiological events in PDAC.

\section{MATERIALS AND METHODS}

\section{Patients and samples}

Patients with surgically resectable PDAC were diagnosed and underwent surgery at the Department of Surgery, Skåne University Hospital, Lund, Sweden, between the year of 1995 and 2011.Archival FFPE tissue samples were obtained from the primary tumor and the tissue blocks were sectioned at a thickness of $10 \mu \mathrm{m}$. The hematoxylin-eosin staining FFPE slides from each patient were carefully reviewed by our pathologist (Figure 9). For each patient, two sections were collected in one tube, which were barcoded to be traceable and referred



Figure 9: Histology images of FFPE slides from two representative cases. H\&E, 10x objective magnification. Left: A long survival PDAC case with histological grade 2. Notice irregular gland formation located in rich stroma. Abnormal epithel imitating normal duct epithel. Adenocarcinoma is situated in upper right part of the picture and infiltrate an atrophied pancreas parenchyma. Right: A short survival PDAC case with histological grade 3. Notice solid area of cancer structures of cells with nuclear pleomorphy and relative scanty cytoplasma. Stroma is not dominant in this picture. 
to their patient identities. These tubes were stored in the South Swedish Biobank, which is located in the Center of Excellence in Biological and Medical Mass Spectrometry (CEBMMS), at the Biomedical Center (BMC), Lund, Sweden. From the biobank, we retrospectively selected patients with PDAC who met the following criteria: 1) "short" survival (<12 months) or "long" survival (> 45 months); 2) resectable disease; 3) tumors located in the head of the pancreas. Accordingly, 9 patients with PDAC with "short" survival and 10 patients with "long" survival were selected for further study. There were no significant differences in terms of pathologically confirmed lymph node metastasis, R1 resection status and use of chemotherapy between "short" and "long" survival groups. The clinical characteristics of the patients are summarized in Table 2. Ethical approval for this study was granted by the institutional review board at Lund University.

\section{Sample preparation}

Two sections of FFPE tissues $(10 \mu \mathrm{m})$ from each patient were obtained and incubated in $1 \mathrm{~mL}$ of 1:50 diluted EnVision ${ }^{\mathrm{TM}}$ FLEX Target Retrieval Solution, High pH (Dako, Glostrup, Copenhagen, Denmark) for 10 min at $97^{\circ} \mathrm{C}$, followed by centrifugation at $14,000 \mathrm{~g}$ for $3 \mathrm{~min}$ and removal of the supernatant. After a repeated de-paraffinization step, the pellets were incubated in $1 \mathrm{~mL} 500 \mathrm{mM}$ Tris- $\mathrm{HCl} \mathrm{pH} 8.0$ at $90^{\circ} \mathrm{C}$ for 1.5 hours to break down cross-linking between proteins and other molecules. This was followed by centrifugation at $14,000 \mathrm{~g}$ at $4^{\circ} \mathrm{C}$ for $15 \mathrm{~min}$, and the supernatant was removed. For denaturation and extraction of proteins, $250 \mu \mathrm{L} 6$ $\mathrm{M}$ Guanidine- $\mathrm{HCl}$ in $50 \mathrm{mM}$ Ammonium bicarbonate (AMBIC) was added and sonication was applied by sonication probe (Branson SLPe, Emerson Electric Co., St. Louis, MO, USA), operating with $20 \%$ amplitude, 5 min for 2 times and 20 seconds cool down period inbetween on ice. After centrifugation at 14,000g for 10 min, the supernatant was stored. Protein concentration was determined by Micro BCA Protein Assay Kit (Thermo Fisher Scientific, San José, CA, USA). For each sample $150 \mu \mathrm{g}$ proteins were diluted by AMBIC in a final volume of $180 \mu \mathrm{L}$ and $7.5 \mu \mathrm{L}$ of chicken lysozyme $(0.02 \mu \mathrm{g} / \mu \mathrm{L})$ was added to evaluate the variance from sample handling and instrument performance among samples. Following reduction with $3 \mathrm{mM}$ DTT $\left(1 \mathrm{~h}\right.$ at $\left.56^{\circ} \mathrm{C}\right)$ and alkylation with $15 \mathrm{mM}$ iodoacetamide ( $30 \mathrm{~min}$ at $24^{\circ} \mathrm{C}$ in dark), the samples underwent precipitation with 1:9 volume ratio of samples to pure ethanol overnight. This was followed by centrifugation at $14,000 \mathrm{~g}$ at $4^{\circ} \mathrm{C}$ for $15 \mathrm{~min}$ and carefully removal of the supernatant. The pellets were dissolved in $200 \mu \mathrm{L}$ AMBIC, followed by adding $1.25 \mu \mathrm{g}$ trypsin (Promega, Madison, WI, USA) for digestion at $37^{\circ} \mathrm{C}$ for 18 h. Peptide concentrations were determined by Micro BCA kit.
Exploiting strong cation exchange by Microspin column (MA SEM HIL-SCX, 10-100 $\mu \mathrm{g}$ capacity, The Nest group Inc., South Borough, MA, USA), $30 \mu \mathrm{g}$ peptides from each sample were separated into 5 fractions by applying step-wise gradient of $20 \mathrm{mM}, 40 \mathrm{mM}, 60 \mathrm{mM}$, $100 \mathrm{mM}$ and $500 \mathrm{mM} \mathrm{KCl}$ in $10 \mathrm{mM} \mathrm{KH}_{2} \mathrm{PO} 4$ containing $20 \% \mathrm{ACN}(\mathrm{pH}=2.8)$. Each fraction underwent desalting by Ultra Microspin Silica C18 column (SUM SS18V, 3-30 $\mu \mathrm{g}$ capacity, The Nest group Inc.). Fractions were dried by centrifugal evaporator and each fraction was resuspended with $30 \mu \mathrm{L}$ of solvent $\mathrm{A}(0.1 \%$ formic acid).

\section{nanoLC-MS/MS analysis (Discovery phase)}

The digested peptides were loaded onto a C18 trap column (Acclaim PepMap 100 pre-column, $2 \mathrm{~cm} \mathrm{x}$ $75 \mu \mathrm{m}$ ID, $3 \mu \mathrm{m}$ particles, $100 \AA$ pore size, PN: 164705 , Thermo Fisher Scientific) and then separated on a C18 analytical column (EASY-Spray column, $25 \mathrm{~cm}$ x $75 \mu \mathrm{m}$ ID, $2 \mu \mathrm{m}$ particles, $100 \AA$ pore size, PN: ES802, Thermo Fisher Scientific). A flow rate of $300 \mathrm{~nL} / \mathrm{min}$ and a column temperature of $35^{\circ} \mathrm{C}$ were applied. A nonlinear gradient was exploited using solvent A $(0.1 \%$ formic acid) and solvent B $(0.1 \%$ formic acid in acetonitrile). The gradient went from $7 \%$ to $26 \% \mathrm{~B}$ during the first $70 \mathrm{~min}$, then increasing to $35 \% \mathrm{~B}$ during the next $20 \mathrm{~min}$, followed by a raise to $90 \% \mathrm{~B}$ in $5 \mathrm{~min}$, which was maintained for $15 \mathrm{~min}$. The total amount of fractionated protein digest injected onto the column was estimated to be $1 \mu \mathrm{g}$. Fractionated samples were injected in the order of increasing salt concentrations used for elution of the peptides. To avoid carryover, each sample injection was followed by a blank injection with solvent A. Each fraction was measured for three times.

The fractionated protein digests were analysed on a Q-Exactive Plus mass spectrometer connected to an EasynLC 1000 pump (Thermo Fisher Scientific) with a top 10 data-dependent acquisition (DDA) method. For ionization, $1.8-2.0 \mathrm{kV}$ of spray voltage and $280^{\circ} \mathrm{C}$ capillary temperature were used. Full MS scans were acquired with the Orbitrap mass analyser over $\mathrm{m} / \mathrm{z}$ 350-1800 range with resolution of 70,000 (at $\mathrm{m} / \mathrm{z} 200$ ), target AGC value of $1 \mathrm{e} 6$ and maximum injection time of $100 \mathrm{~ms}$. The ten most intense peaks with charge state $>=2$ were fragmented in the HCD collision cell with normalized collision energy of $30 \%$, and tandem mass spectra were acquired in the Orbitrap mass analyzer with resolution of 35,000 (at $\mathrm{m} / \mathrm{z}$ 200), target AGC value of $1 \mathrm{e} 6$ and maximum injection time of $120 \mathrm{~ms}$. The ion selection threshold was set to $4.2 \mathrm{e} 4$ and dynamic exclusion was $20 \mathrm{~s}$.

\section{Verification by parallel reaction monitoring}

Using unfractionated protein digests from each sample, a targeted proteomic method, parallel reaction monitoring (PRM) was employed to verify the 


\begin{tabular}{lll}
\hline & PDAC (SS) & PDAC (LS) \\
\hline Sex (female/male) & $3 / 6$ & $7 / 3$ \\
Age [median (range), year] & $64(48-74)$ & $71(43-77)$ \\
Diabetes mellitus & 5 & 4 \\
Tumor location & & 10 \\
$\quad$ pancreas head & 9 & $3(2-7)$ \\
Tumor diameter (cm) & $2.5(1-6)$ & 7 \\
Lymph node metastasis & 4 & \\
Staging & & 3 \\
$\quad$ IIA & 5 & 7 \\
$\quad$ IIB & 4 & 3 \\
R1 resection & 4 & 10 \\
Surgery & 9 & 9 \\
Adjuvant chemotherapy & 5 & 5 \\
Gemcitabine & 3 & 1 \\
5-FU & 1 & 2 \\
Capecitabine & 0 & 0 \\
Gemcitabine, 5-FU & 1 & 1 \\
Gemcitabine, Capecitabine & 0 & 0 \\
Radiotherapy & 1 & $59.1(47.0-120.9)$ \\
Survival (mean (SD), month) & $7.3(1.9-11.5)$ & \\
\hline
\end{tabular}

Abbreviations: PDAC: Pancreatic ductal adenocarcinoma; SS: short survival; LS: long survival.

differentially expressed proteins. One or two unique peptides of each protein of interest were selected. A panel of 110 peptides from 73 proteins was finally scheduled in one run to verify potentially prognostic proteins in 10 patients with "long" survival and 9 patients with "short" survival. Five peptides from chicken lysozyme and five PRTC peptides (Product no 88320, Pierce, Rockford, IL, USA) were added to the PRM panel to evaluate the experimental process. The samples were prepared in the same way as it was described previously but without $\mathrm{SCX}$ fractionation. The retention time, precursor $\mathrm{m} / \mathrm{z}$ and charge state of peptides was referred to the prior DDA experiments. The retention times and transitions were further modified and confirmed in several preliminary PRM runs. The same LC-MS platform was applied for the PRM study. A total of $1 \mu \mathrm{g}$ peptide was injected and the same LC parameters were used for the separation. Targeted $\mathrm{MS}^{2}$ mode was operated with time-scheduled acquisition of the selected peptides in $+/-5$ min retention time windows. PRM scanning was performed at 17,500 resolution (AGC target $1 \times 10^{5}, 50 \mathrm{~ms}$ maximum injection time) as triggered by a scheduled inclusion list. The chromatographic peak width is $30 \mathrm{~s}$. Fragmentation was performed with normalized collision energy of 27 and MS/ MS scans were acquired with a resolution of 70,000 at $\mathrm{m} / \mathrm{z} 200$.

\section{Statistics and bioinformatics}

Exploiting multidimensional protein identification technology (MudPIT), the data from 5 fractions of each sample were submitted together to Sequest HT search engine in Proteome Discoverer 1.4, being processed as one continuous input file for protein identification and quantification. The quantification of protein intensities is based on the averaged intensities of their three most abundant peptides. Uniprot Human Reviewed (released 2013/09) was referred as search database. Decoy database containing reversed version of all protein sequences were added for the monitoring of false discovery rate (FDR). For the identification of peptides, precursor and fragment mass tolerances were $10 \mathrm{ppm}$ and $0.02 \mathrm{Da}$ respectively. Oxidation and carbamidomethylation were taken into consideration as variable and static modifications, respectively, and one maximum missed cleavage site was allowed. Proteins were identified based on at least two peptides with high confidence (FDR $<1 \%$ ). Precursor ions area detector was applied in the search engine for the quantification of peptides. Redundant proteins were automatically grouped by default. Perseus software [90] was used for the statistics. Those proteins that were detected in less than half $(<5)$ of the samples in both groups were excluded from further analysis. To minimize 
the technical variance introduced by sample handling and instrument, each sample was run for three times (replicates) whereas the intensities of proteins in each replicate were normalized to its median intensity. Log 2 transformation was applied to the normalized intensities to make the data normally distributed and suitable for further statistics. Missing values were replaced from random numbers drawn from a normal distribution, which represents low abundance measurements (default setting). Using Student's $t$-test, protein intensities were compared between two groups based on the average of log 2 transformed normalized protein intensities in each sample. Proteins were also defined as differentially expressed if detected more frequently ( $\geq 5$ samples) in one group than in the other group. Hierarchical clustering and principal component analysis were also performed to visualize any significant differences between two groups. Skyline software was used for MS1 filtering and MS1 quantitation in the PRM study. The intensities of targeted peptide of each protein were log 2 transformed and then compared between groups by Student's $t$-test. For those proteins having two targeted peptides, the peptide with higher intensity will be compared. The bioinformatics analysis of relationship networks between differentially expressed proteins used STRING [19] and Ingenuity Pathway Analysis (IPA, Qiagen, Inc. Redwood City, CA, USA). Assessment of overrepresented functional annotations and pathways was performed using Gene Ontology resources [91], Panther [92], Reactome [93], David [94] and IPA. In David, Panther and IPA, the whole sets of proteins detected in the study were used as analysis backgrounds.

\section{Abbreviations}

$\mathrm{CV}$ : coefficient of variation; DDA: datadependent acquisition; ECM: extracellular matrix; FDR: false discovery rate; FFPE: formalin-fixed paraffinembedded; IPA: Ingenuity Pathway Analysis; MMPs: matrix metalloproteases; MudPIT: multidimensional protein identification technology; PC: Pancreatic cancer; PDAC: pancreatic ductal adenocarcinoma; PMNs: polymorphonuclear neutrophils; PRM: parallel reaction monitoring; PSMs: peptide-spectrum matches.

\section{ACKNOWLEDGMENTS}

We thank Katarzyna Said Hilmersson, Yutaka Sugihara and Henrik Lindberg for the technical support. The study was supported by SWElife/Vinnova, the Royal Physiographic Society of Lund, the Magnus Bergvall Foundation, the Tore Nilsson Foundation and the Inga and John Hain's Foundation for Medical Research.

\section{CONFLICTS OF INTEREST}

The authors declare no conflicts of interest.

\section{REFERENCES}

1. Siegel RL, Miller KD, Jemal A. Cancer Statistics, 2017. CA Cancer J Clin. 2017; 67:7-30. https://doi.org/10.3322/ caac. 21387.

2. Rahib L, Smith BD, Aizenberg R, Rosenzweig AB, Fleshman JM, Matrisian LM. Projecting cancer incidence and deaths to 2030: the unexpected burden of thyroid, liver, and pancreas cancers in the United States. Cancer Res. 2014; 74:2913-21. https://doi.org/10.1158/0008-5472. CAN-14-0155.

3. Goonetilleke KS, Siriwardena AK. Systematic review of carbohydrate antigen (CA 19-9) as a biochemical marker in the diagnosis of pancreatic cancer. Eur J Surg Oncol. 2007; 33:266-70. https://doi.org/10.1016/j.ejso.2006.10.004.

4. Yachida S, Jones S, Bozic I, Antal T, Leary R, Fu B, Kamiyama M, Hruban RH, Eshleman JR, Nowak MA, Velculescu VE, Kinzler KW, Vogelstein B, et al. Distant metastasis occurs late during the genetic evolution of pancreatic cancer. Nature. 2010; 467:1114-17. https://doi. org/10.1038/nature09515.

5. Notta F, Chan-Seng-Yue M, Lemire M, Li Y, Wilson GW, Connor AA, Denroche RE, Liang SB, Brown AM, Kim JC, Wang T, Simpson JT, Beck T, et al. A renewed model of pancreatic cancer evolution based on genomic rearrangement patterns. Nature. 2016; 538:378-82. https:// doi.org/10.1038/nature19823.

6. Ansari D, Bauden M, Bergström S, Rylance R, MarkoVarga G, Andersson R. Relationship between tumour size and outcome in pancreatic ductal adenocarcinoma. Br J Surg. 2017; 104:600-07. https://doi.org/10.1002/bjs.10471.

7. Waddell N, Pajic M, Patch AM, Chang DK, Kassahn KS, Bailey P, Johns AL, Miller D, Nones K, Quek K, Quinn MC, Robertson AJ, Fadlullah MZ, et al, and Australian Pancreatic Cancer Genome Initiative. Whole genomes redefine the mutational landscape of pancreatic cancer. Nature. 2015; 518:495-501. https://doi.org/10.1038/ nature 14169.

8. Makohon-Moore A, Iacobuzio-Donahue CA. Pancreatic cancer biology and genetics from an evolutionary perspective. Nat Rev Cancer. 2016; 16:553-65. https://doi. org/10.1038/nrc.2016.66.

9. Collisson EA, Sadanandam A, Olson P, Gibb WJ, Truitt M, Gu S, Cooc J, Weinkle J, Kim GE, Jakkula L, Feiler HS, Ko AH, Olshen AB, et al. Subtypes of pancreatic ductal adenocarcinoma and their differing responses to therapy. Nat Med. 2011; 17:500-03. https://doi.org/10.1038/ nm.2344.

10. Moffitt RA, Marayati R, Flate EL, Volmar KE, Loeza SG, Hoadley KA, Rashid NU, Williams LA, Eaton SC, Chung AH, Smyla JK, Anderson JM, Kim HJ, et al. Virtual microdissection identifies distinct tumor- and stromaspecific subtypes of pancreatic ductal adenocarcinoma. Nat Genet. 2015; 47:1168-78. https://doi.org/10.1038/ng.3398. 
11. Sun C, Rosendahl AH, Ansari D, Andersson R. Proteome-based biomarkers in pancreatic cancer. World J Gastroenterol. 2011; 17:4845-52. https://doi.org/10.3748/ wjg.v17.i44.4845.

12. Ansari D, Aronsson L, Sasor A, Welinder C, Rezeli M, Marko-Varga G, Andersson R. The role of quantitative mass spectrometry in the discovery of pancreatic cancer biomarkers for translational science. J Transl Med. 2014; 12:87. https://doi.org/10.1186/1479-5876-12-87.

13. Turtoi A, Musmeci D, Wang Y, Dumont B, Somja J, Bevilacqua G, De Pauw E, Delvenne P, Castronovo V. Identification of novel accessible proteins bearing diagnostic and therapeutic potential in human pancreatic ductal adenocarcinoma. J Proteome Res. 2011; 10:4302-13. https://doi.org/10.1021/pr200527z.

14. Takadate T, Onogawa T, Fukuda T, Motoi F, Suzuki T, Fujii K, Kihara M, Mikami S, Bando Y, Maeda S, Ishida $\mathrm{K}$, Minowa T, Hanagata N, et al. Novel prognostic protein markers of resectable pancreatic cancer identified by coupled shotgun and targeted proteomics using formalinfixed paraffin-embedded tissues. Int J Cancer. 2013; 132:1368-82. https://doi.org/10.1002/ijc.27797.

15. Chen R, Pan S, Ottenhof NA, de Wilde RF, Wolfgang CL, Lane Z, Post J, Bronner MP, Willmann JK, Maitra A, Brentnall TA. Stromal galectin-1 expression is associated with long-term survival in resectable pancreatic ductal adenocarcinoma. Cancer Biol Ther. 2012; 13:899-907. https://doi.org/10.4161/cbt.20842.

16. Kuwae Y, Kakehashi A, Wakasa K, Wei M, Yamano S, Ishii N, Ohsawa M, Wanibuchi H. Paraneoplastic Ma AntigenLike 1 as a potential prognostic biomarker in human pancreatic ductal adenocarcinoma. Pancreas. 2015; 44:10615. https://doi.org/10.1097/MPA.0000000000000220.

17. Brand RE, Nolen BM, Zeh HJ, Allen PJ, Eloubeidi MA, Goldberg M, Elton E, Arnoletti JP, Christein JD, Vickers SM, Langmead CJ, Landsittel DP, Whitcomb DC, et al. Serum biomarker panels for the detection of pancreatic cancer. Clin Cancer Res. 2011; 17:805-16. https://doi. org/10.1158/1078-0432.CCR-10-0248.

18. Kojima K, Bowersock GJ, Kojima C, Klug CA, Grizzle WE, Mobley JA. Validation of a robust proteomic analysis carried out on formalin-fixed paraffin-embedded tissues of the pancreas obtained from mouse and human. Proteomics. 2012; 12:3393-402. https://doi.org/10.1002/ pmic. 201100663.

19. Szklarczyk D, Franceschini A, Wyder S, Forslund K, Heller D, Huerta-Cepas J, Simonovic M, Roth A, Santos A, Tsafou KP, Kuhn M, Bork P, Jensen LJ, et al. STRING v10: protein-protein interaction networks, integrated over the tree of life. Nucleic Acids Res. 2015; 43:D447-52. https:// doi.org/10.1093/nar/gku1003.

20. Adham M, Jaeck D, Le Borgne J, Oussoultzouglou E, Chenard-Neu MP, Mosnier JF, Scoazec JY, Mornex F, Partensky C. Long-term survival (5-20 years) after pancreatectomy for pancreatic ductal adenocarcinoma: a series of 30 patients collected from 3 institutions. Pancreas. 2008; 37:352-57. https://doi.org/10.1097/ MPA.0b013e31818166d2.

21. Shin SH, Kim SC, Hong SM, Song KB, Lee JH, Park KM, Lee YJ. Can statistically determined prognostic factors predict the long-term survival of patients with pancreatic ductal adenocarcinoma following surgical resection?: clinicopathological analysis of 82 long-term survivors. Pancreas. 2014; 43:571-77. https://doi.org/10.1097/ MPA.0000000000000063.

22. Stark AP, Sacks GD, Rochefort MM, Donahue TR, Reber HA, Tomlinson JS, Dawson DW, Eibl G, Hines OJ. Long-term survival in patients with pancreatic ductal adenocarcinoma. Surgery. 2016; 159:1520-27. https://doi. org/10.1016/j.surg.2015.12.024.

23. Chen R, Dawson DW, Pan S, Ottenhof NA, de Wilde RF, Wolfgang CL, May DH, Crispin DA, Lai LA, Lay AR, Waghray M, Wang S, McIntosh MW, et al. Proteins associated with pancreatic cancer survival in patients with resectable pancreatic ductal adenocarcinoma. Lab Invest. 2015; 95:43-55. https://doi.org/10.1038/labinvest.2014.128.

24. Pavlova NN, Thompson CB. The Emerging Hallmarks of Cancer Metabolism. Cell Metab. 2016; 23:27-47. https:// doi.org/10.1016/j.cmet.2015.12.006.

25. Chan AK, Bruce JI, Siriwardena AK. Glucose metabolic phenotype of pancreatic cancer. World J Gastroenterol. 2016; 22:3471-85. https://doi.org/10.3748/wjg.v22. i12.3471.

26. Nagarajan A, Dogra SK, Sun L, Gandotra N, Ho T, Cai G, Cline G, Kumar P, Cowles RA, Wajapeyee N. Paraoxonase 2 Facilitates Pancreatic Cancer Growth and Metastasis by Stimulating GLUT1-Mediated Glucose Transport. Mol Cell. 2017; 67:685-701.e6. https://doi.org/10.1016/j. molcel.2017.07.014.

27. Cai X, Ding H, Liu Y, Pan G, Li Q, Yang Z, Liu W. Expression of HMGB2 indicates worse survival of patients and is required for the maintenance of Warburg effect in pancreatic cancer. Acta Biochim Biophys Sin (Shanghai). 2017; 49:119-27. https://doi.org/10.1093/abbs/gmw124.

28. Liu W, Zhang B, Hu Q, Qin Y, Xu W, Shi S, Liang C, Meng Q, Xiang J, Liang D, Ji S, Liu J, Hu P, et al. A new facet of NDRG1 in pancreatic ductal adenocarcinoma: suppression of glycolytic metabolism. Int J Oncol. 2017; 50:1792-800. https://doi.org/10.3892/ijo.2017.3938.

29. Chikamoto A, Inoue R, Komohara Y, Sakamaki K, Hashimoto D, Shiraishi S, Takamori H, Yamashita YI, Yoshida N, Yamanaka T, Yamashita Y, Baba H. Preoperative high maximum standardized uptake value in association with glucose transporter 1 predicts poor prognosis in pancreatic cancer. Ann Surg Oncol. 2017; 24:2040-46. https://doi.org/10.1245/s10434-017-5799-1.

30. Davis-Yadley AH, Abbott AM, Pimiento JM, Chen DT, Malafa MP. Increased expression of the glucose transporter type 1 gene is associated with worse overall survival in resected pancreatic adenocarcinoma. 
Pancreas. 2016; 45:974-79. https://doi.org/10.1097/ MPA.0000000000000580.

31. Shibuya K, Okada M, Suzuki S, Seino M, Seino S, Takeda $\mathrm{H}$, Kitanaka C. Targeting the facilitative glucose transporter GLUT1 inhibits the self-renewal and tumor-initiating capacity of cancer stem cells. Oncotarget. 2015; 6:651-61. https://doi.org/10.18632/oncotarget.2892.

32. Bailey P, Chang DK, Nones K, Johns AL, Patch AM, Gingras MC, Miller DK, Christ AN, Bruxner TJ, Quinn MC, Nourse C, Murtaugh LC, Harliwong I, et al, and Australian Pancreatic Cancer Genome Initiative. Genomic analyses identify molecular subtypes of pancreatic cancer. Nature. 2016; 531:47-52. https://doi.org/10.1038/nature16965.

33. Lüttges J, Galehdari H, Bröcker V, Schwarte-Waldhoff I, Henne-Bruns D, Klöppel G, Schmiegel W, Hahn SA. Allelic loss is often the first hit in the biallelic inactivation of the p53 and DPC4 genes during pancreatic carcinogenesis. Am J Pathol. 2001; 158:1677-83. https://doi.org/10.1016/ S0002-9440(10)64123-5.

34. Moyer MT, Gaffney RR. Pancreatic adenocarcinoma. N Engl J Med. 2014; 371:2140. https://doi.org/10.1056/ NEJMc1412266\#SA2.

35. Oshima M, Okano K, Muraki S, Haba R, Maeba T, Suzuki Y, Yachida S. Immunohistochemically detected expression of 3 major genes (CDKN2A/p16, TP53, and SMAD4/ DPC4) strongly predicts survival in patients with resectable pancreatic cancer. Ann Surg. 2013; 258:336-46. https://doi. org/10.1097/SLA.0b013e3182827a65.

36. Tobita K, Kijima H, Dowaki S, Oida Y, Kashiwagi H, Ishii M, Sugio Y, Sekka T, Ohtani Y, Tanaka M, Inokuchi S, Makuuchi H. Thrombospondin-1 expression as a prognostic predictor of pancreatic ductal carcinoma. Int J Oncol. 2002; 21:1189-95.

37. Xu Y, Li Z, Jiang P, Wu G, Chen K, Zhang X, Li X. The co-expression of MMP-9 and Tenascin-C is significantly associated with the progression and prognosis of pancreatic cancer. Diagn Pathol. 2015; 10:211. https://doi.org/10.1186/ s13000-015-0445-3.

38. Dameron KM, Volpert OV, Tainsky MA, Bouck N. Control of angiogenesis in fibroblasts by p53 regulation of thrombospondin-1. Science. 1994; 265:1582-84. https://doi. org/10.1126/science.7521539.

39. Li P, Yao H, Zhang Z, Li M, Luo Y, Thompson PR, Gilmour DS, Wang Y. Regulation of p53 target gene expression by peptidylarginine deiminase 4. Mol Cell Biol. 2008; 28:4745-58. https://doi.org/10.1128/MCB.01747-07.

40. Tanikawa C, Espinosa M, Suzuki A, Masuda K, Yamamoto K, Tsuchiya E, Ueda K, Daigo Y, Nakamura Y, Matsuda K. Regulation of histone modification and chromatin structure by the p53-PADI4 pathway. Nat Commun. 2012; 3:676. https://doi.org/10.1038/ncomms1676.

41. Cheng JC, Auersperg N, Leung PC. Inhibition of p53 represses E-cadherin expression by increasing DNA methyltransferase-1 and promoter methylation in serous borderline ovarian tumor cells. Oncogene. 2011; 30:393042. https://doi.org/10.1038/onc.2011.117.

42. Sankpal NV, Willman MW, Fleming TP, Mayfield JD, Gillanders WE. Transcriptional repression of epithelial cell adhesion molecule contributes to p53 control of breast cancer invasion. Cancer Res. 2009; 69:753-57. https://doi. org/10.1158/0008-5472.CAN-08-2708.

43. Akita H, Nagano H, Takeda Y, Eguchi H, Wada H, Kobayashi S, Marubashi S, Tanemura M, Takahashi H, Ohigashi H, Tomita Y, Ishikawa O, Mori M, et al. EpCAM is a significant prognostic factor in pancreatic cancer patients by suppressing cell activity. Oncogene. 2011; 30:3468-76. https://doi.org/10.1038/onc.2011.59.

44. Fong D, Moser P, Kasal A, Seeber A, Gastl G, Martowicz A, Wurm M, Mian C, Obrist P, Mazzoleni G, Spizzo G. Loss of membranous expression of the intracellular domain of EpCAM is a frequent event and predicts poor survival in patients with pancreatic cancer. Histopathology. 2014; 64:683-92. https://doi.org/10.1111/his.12307.

45. Neesse A, Algül H, Tuveson DA, Gress TM. Stromal biology and therapy in pancreatic cancer: a changing paradigm. Gut. 2015; 64:1476-84. https://doi.org/10.1136/ gutjnl-2015-309304.

46. Erkan M, Michalski CW, Rieder S, Reiser-Erkan C, Abiatari I, Kolb A, Giese NA, Esposito I, Friess H, Kleeff $\mathrm{J}$. The activated stroma index is a novel and independent prognostic marker in pancreatic ductal adenocarcinoma. Clin Gastroenterol Hepatol. 2008; 6:1155-61. https://doi. org/10.1016/j.cgh.2008.05.006.

47. Waghray M, Yalamanchili M, di Magliano MP, Simeone DM. Deciphering the role of stroma in pancreatic cancer. Curr Opin Gastroenterol. 2013; 29:537-43. https://doi. org/10.1097/MOG.0b013e328363affe.

48. Ansari D, Carvajo M, Bauden M, Andersson R. Pancreatic cancer stroma: controversies and current insights. Scand J Gastroenterol. 2017; 52:641-46. https://doi.org/10.1080/00 365521.2017 .1293726$.

49. Lee JJ, Perera RM, Wang H, Wu DC, Liu XS, Han S, Fitamant J, Jones PD, Ghanta KS, Kawano S, Nagle JM, Deshpande V, Boucher Y, et al. Stromal response to Hedgehog signaling restrains pancreatic cancer progression. Proc Natl Acad Sci USA. 2014; 111:E3091-100. https://doi. org/10.1073/pnas.1411679111.

50. Özdemir BC, Pentcheva-Hoang T, Carstens JL, Zheng X, Wu CC, Simpson TR, Laklai H, Sugimoto H, Kahlert C, Novitskiy SV, De Jesus-Acosta A, Sharma P, Heidari $\mathrm{P}$, et al. Depletion of carcinoma-associated fibroblasts and fibrosis induces immunosuppression and accelerates pancreas cancer with reduced survival. Cancer Cell. 2014; 25:719-34. https://doi.org/10.1016/j.ccr.2014.04.005.

51. Rucki AA, Zheng L. Pancreatic cancer stroma: understanding biology leads to new therapeutic strategies. World J Gastroenterol. 2014; 20:2237-46. https://doi. org/10.3748/wjg.v20.i9.2237. 
52. Xiong G, Deng L, Zhu J, Rychahou PG, Xu R. Prolyl-4hydroxylase $\alpha$ subunit 2 promotes breast cancer progression and metastasis by regulating collagen deposition. BMC Cancer. 2014; 14:1. https://doi.org/10.1186/1471-2407-14-1.

53. Topalovski M, Brekken RA. Matrix control of pancreatic cancer: new insights into fibronectin signaling. Cancer Lett. 2016; 381:252-58. https://doi.org/10.1016/j. canlet.2015.12.027.

54. Macpherson IR, Rainero E, Mitchell LE, van den Berghe PV, Speirs C, Dozynkiewicz MA, Chaudhary S, Kalna G, Edwards J, Timpson P, Norman JC. CLIC3 controls recycling of late endosomal MT1-MMP and dictates invasion and metastasis in breast cancer. J Cell Sci. 2014; 127:3893-901. https://doi.org/10.1242/jcs.135947.

55. Morgan RG, Ridsdale J, Tonks A, Darley RL. Factors affecting the nuclear localization of $\beta$-catenin in normal and malignant tissue. J Cell Biochem. 2014; 115:1351-61. https://doi.org/10.1002/jcb.24803.

56. Pramanik KC, Fofaria NM, Gupta P, Ranjan A, Kim SH, Srivastava SK. Inhibition of $\beta$-catenin signaling suppresses pancreatic tumor growth by disrupting nuclear $\beta$-catenin/ TCF-1 complex: critical role of STAT-3. Oncotarget. 2015; 6:11561-74. https://doi.org/10.18632/oncotarget.3427.

57. White BD, Chien AJ, Dawson DW. Dysregulation of Wnt/ $\beta$-catenin signaling in gastrointestinal cancers. Gastroenterology. 2012; 142:219-32. https://doi. org/10.1053/j.gastro.2011.12.001.

58. Zhan T, Rindtorff N, Boutros M. Wnt signaling in cancer. Oncogene. 2017; 36:1461-73. https://doi.org/10.1038/ onc. 2016.304 .

59. Vincent A, Omura N, Hong SM, Jaffe A, Eshleman J, Goggins M. Genome-wide analysis of promoter methylation associated with gene expression profile in pancreatic adenocarcinoma. Clin Cancer Res. 2011; 17:4341-54. https://doi.org/10.1158/1078-0432.CCR-10-3431.

60. Zeng G, Germinaro M, Micsenyi A, Monga NK, Bell A, Sood A, Malhotra V, Sood N, Midda V, Monga DK, Kokkinakis DM, Monga SP. Aberrant Wnt/beta-catenin signaling in pancreatic adenocarcinoma. Neoplasia. 2006; 8:279-89. https://doi.org/10.1593/neo.05607.

61. Zhang Y, Morris JP 4th, Yan W, Schofield HK, Gurney A, Simeone DM, Millar SE, Hoey T, Hebrok M, Pasca di Magliano M. Canonical wnt signaling is required for pancreatic carcinogenesis. Cancer Res. 2013; 73:4909-22. https://doi.org/10.1158/0008-5472.CAN-12-4384.

62. Fridlender ZG, Sun J, Kim S, Kapoor V, Cheng G, Ling L, Worthen GS, Albelda SM. Polarization of tumor-associated neutrophil phenotype by TGF-beta: "N1" versus "N2" TAN. Cancer Cell. 2009; 16:183-94. https://doi.org/10.1016/j. ccr.2009.06.017.

63. Ino Y, Yamazaki-Itoh R, Shimada K, Iwasaki M, Kosuge T, Kanai Y, Hiraoka N. Immune cell infiltration as an indicator of the immune microenvironment of pancreatic cancer. Br J Cancer. 2013; 108:914-23. https://doi.org/10.1038/bjc.2013.32.
64. Reid MD, Basturk O, Thirabanjasak D, Hruban RH, Klimstra DS, Bagci P, Altinel D, Adsay V. Tumor-infiltrating neutrophils in pancreatic neoplasia. Mod Pathol. 2011; 24:1612-19. https://doi.org/10.1038/modpathol.2011.113.

65. Gregory AD, Houghton AM. Tumor-associated neutrophils: new targets for cancer therapy. Cancer Res. 2011; 71:241116. https://doi.org/10.1158/0008-5472.CAN-10-2583.

66. Jones LE, Humphreys MJ, Campbell F, Neoptolemos JP, Boyd MT. Comprehensive analysis of matrix metalloproteinase and tissue inhibitor expression in pancreatic cancer: increased expression of matrix metalloproteinase-7 predicts poor survival. Clin Cancer Res. 2004; 10:2832-45. https://doi.org/10.1158/1078-0432.CCR-1157-03.

67. Egeblad M, Werb Z. New functions for the matrix metalloproteinases in cancer progression. Nat Rev Cancer. 2002; 2:161-74. https://doi.org/10.1038/nrc745.

68. Owen CA. Leukocyte cell surface proteinases: regulation of expression, functions, and mechanisms of surface localization. Int J Biochem Cell Biol. 2008; 40:1246-72. https://doi.org/10.1016/j.biocel.2008.01.020.

69. Wiedl T, Collaud S, Hillinger S, Arni S, Burgess C, Kroll W, Schraml P, Soltermann A, Moch H, Weder W. KRAS mutation is associated with elevated myeloblastin activity in human lung adenocarcinoma. Cancer Genomics Proteomics. 2012; 9:51-54.

70. Bories D, Raynal MC, Solomon DH, Darzynkiewicz $Z$, Cayre YE. Down-regulation of a serine protease, myeloblastin, causes growth arrest and differentiation of promyelocytic leukemia cells. Cell. 1989; 59:959-68. https://doi.org/10.1016/0092-8674(89)90752-6.

71. Pawłowski K, Lepistö M, Meinander N, Sivars U, Varga M, Wieslander E. Novel conserved hydrolase domain in the CLCA family of alleged calcium-activated chloride channels. Proteins. 2006; 63:424-39. https://doi. org/10.1002/prot.20887.

72. Sala-Rabanal M, Yurtsever Z, Nichols CG, Brett TJ. Secreted CLCA1 modulates TMEM16A to activate $\mathrm{Ca}(2+)$ dependent chloride currents in human cells. eLife. 2015; 4. https://doi.org/10.7554/eLife.05875.

73. Walia V, Yu Y, Cao D, Sun M, McLean JR, Hollier BG, Cheng J, Mani SA, Rao K, Premkumar L, Elble RC. Loss of breast epithelial marker hCLCA2 promotes epithelialto-mesenchymal transition and indicates higher risk of metastasis. Oncogene. 2012; 31:2237-46. https://doi. org/10.1038/onc.2011.392.

74. Yu Y, Walia V, Elble RC. Loss of CLCA4 promotes epithelial-to-mesenchymal transition in breast cancer cells. PLoS One. 2013; 8:e83943. https://doi.org/10.1371/journal. pone. 0083943.

75. Yang B, Cao L, Liu B, McCaig CD, Pu J. The transition from proliferation to differentiation in colorectal cancer is regulated by the calcium activated chloride channel A1. PLoS One. 2013; 8:e60861. https://doi.org/10.1371/journal. pone. 0060861 . 
76. Yang B, Cao L, Liu J, Xu Y, Milne G, Chan W, Heys SD, McCaig $\mathrm{CD}, \mathrm{Pu}$ J. Low expression of chloride channel accessory 1 predicts a poor prognosis in colorectal cancer. Cancer. 2015; 121:1570-80. https://doi.org/10.1002/ cncr.29235.

77. Sala-Rabanal M, Yurtsever Z, Berry KN, Nichols CG, Brett TJ. Modulation of TMEM16A channel activity by the von Willebrand factor type A (VWA) domain of the calciumactivated chloride channel regulator 1 (CLCA1). J Biol Chem. 2017; 292:9164-74. https://doi.org/10.1074/jbc. M117.788232.

78. Lang F, Stournaras C. Ion channels in cancer: future perspectives and clinical potential. Philos Trans R Soc Lond B Biol Sci. 2014; 369:20130108. https://doi.org/10.1098/ rstb.2013.0108.

79. Stock C, Schwab A. Ion channels and transporters in metastasis. Biochim Biophys Acta. 2015; 1848:2638-46. https://doi.org/10.1016/j.bbamem.2014.11.012.

80. Arcangeli A, Crociani O, Bencini L. Interaction of tumour cells with their microenvironment: ion channels and cell adhesion molecules. A focus on pancreatic cancer. Philos Trans R Soc Lond B Biol Sci. 2014; 369:20130101. https:// doi.org/10.1098/rstb.2013.0101.

81. Stehling O, Mascarenhas J, Vashisht AA, Sheftel AD, Niggemeyer B, Rösser R, Pierik AJ, Wohlschlegel JA, Lill R. Human CIA2A-FAM96A and CIA2B-FAM96B integrate iron homeostasis and maturation of different subsets of cytosolic-nuclear iron-sulfur proteins. Cell Metab. 2013; 18:187-98. https://doi.org/10.1016/j.cmet.2013.06.015.

82. Schwamb B, Pick R, Fernández SB, Völp K, Heering J, Dötsch V, Bösser S, Jung J, Beinoraviciute-Kellner R, Wesely J, Zörnig I, Hammerschmidt M, Nowak M, et al. FAM96A is a novel pro-apoptotic tumor suppressor in gastrointestinal stromal tumors. Int J Cancer. 2015; 137:1318-29. https://doi.org/10.1002/ijc.29498.

83. Altree-Tacha D, Tyrrell J, Haas T. CDH17 Is a more sensitive marker for gastric adenocarcinoma than CK20 and CDX2. Arch Pathol Lab Med. 2017; 141:144-50. https:// doi.org/10.5858/arpa.2015-0404-OA.

84. Zhao T, Jiang W, Wang X, Wang H, Zheng C, Li Y, Sun Y, Huang C, Han ZB, Yang S, Jia Z, Xie K, Ren H, et al. ESE3 inhibits pancreatic cancer metastasis by upregulating E-cadherin. Cancer Res. 2017; 77:874-85. https://doi. org/10.1158/0008-5472.CAN-16-2170.
85. Kuhlmann L, Nadler WM, Kerner A, Hanke SA, Noll EM, Eisen C, Espinet E, Vogel V, Trumpp A, Sprick MR, Roesli $\mathrm{CP}$. Identification and validation of novel subtype-specific protein biomarkers in pancreatic ductal adenocarcinoma. Pancreas. 2017; 46:311-22. https://doi.org/10.1097/ MPA.0000000000000743.

86. Pawłowski K. Uncharacterized/hypothetical proteins in biomedical 'omics' experiments: is novelty being swept under the carpet? Brief Funct Genomics Proteomics. 2008; 7:283-90. https://doi.org/10.1093/bfgp/eln033.

87. Zallot R, Brochier-Armanet C, Gaston KW, Forouhar F, Limbach PA, Hunt JF, de Crécy-Lagard V. Plant, animal, and fungal micronutrient queuosine is salvaged by members of the DUF2419 protein family. ACS Chem Biol. 2014; 9:1812-25. https://doi.org/10.1021/cb500278k.

88. Tuorto F, Lyko F. Genome recoding by tRNA modifications. Open Biol. 2016; 6:160287. https://doi.org/10.1098/ rsob. 160287.

89. Vinayak M, Pathak C. Queuosine modification of tRNA: its divergent role in cellular machinery. Biosci Rep. 2009; 30:135-48. https://doi.org/10.1042/BSR20090057.

90. Tyanova S, Temu T, Sinitcyn P, Carlson A, Hein MY, Geiger T, Mann M, Cox J. The Perseus computational platform for comprehensive analysis of (prote)omics data. Nat Methods. 2016; 13:731-40. https://doi.org/10.1038/nmeth.3901.

91. Gene Ontology C, and Gene Ontology Consortium. Gene Ontology Consortium: going forward. Nucleic Acids Res. 2015; 43:D1049-56. https://doi.org/10.1093/nar/gku1179.

92. Mi H, Huang X, Muruganujan A, Tang H, Mills C, Kang D, Thomas PD. PANTHER version 11: expanded annotation data from Gene Ontology and Reactome pathways, and data analysis tool enhancements. Nucleic Acids Res. 2017; 45:D183-89. https://doi.org/10.1093/nar/gkw1138.

93. Fabregat A, Sidiropoulos K, Garapati P, Gillespie M, Hausmann K, Haw R, Jassal B, Jupe S, Korninger F, McKay S, Matthews L, May B, Milacic M, et al. The Reactome pathway Knowledgebase. Nucleic Acids Res. 2016; 44:D481-87. https://doi.org/10.1093/nar/gkv1351.

94. Huang W, Sherman BT, Lempicki RA. Systematic and integrative analysis of large gene lists using DAVID bioinformatics resources. Nat Protoc. 2009; 4:44-57. https://doi.org/10.1038/nprot.2008.211. 